\title{
Atrial Septal Aneurysm and Atrial Arrhythmia: A Review of The Literatures
}

\author{
Long Yang*, Jionghong He and Ye Tian \\ Cardiology Department of Guizhou Provincial People's Hospital, China
}

*Corresponding author: Long Yang, Guizhou Provincial Hospital, Guizhou Province, N0.83 Zhongshandonglu Road, Guiyang City 550002, China

\begin{tabular}{ll}
\hline ARTICLE INFO & ABSTRACT \\
\hline
\end{tabular}

Received: 慧 February 13, 2019

Published: 慧 February 25, 2019

Citation: Long Y, Jionghong $\mathrm{H}, \mathrm{Ye} \mathrm{T}$. Atrial Septal Aneurysm and Atrial Arrhythmia: A Review of The Literatures. Biomed J Sci \& Tech Res 15(1)-2019. BJSTR. MS.ID.002654.
This paper is a brief review of literatures about the relationship between atrial septal aneurysm and atrial arrhythmia.

Keywords: Atrial Septal Aneurysm; Atrial Arrhythmia

\section{Introduction}

Atrial Septal Aneurysm (ASA). is a saccular deformity located in the atrial septum [1]. The first report on ASA was published by Lang and Posselt in 1934. It is a localized bulging of the interatrial septum and the diagnostic criteria is usually a protrusion $>6$ $\mathrm{mm}$ into the right atrium or left atrium or both atriums [2]. The pathogenesis of atrial septal aneurysm might be explained by an abnormal structure of the interatrial septum, by a change in the normal inter-atrial pressure gradient, or by both. Although ASA is a well-recognized cardiac anomaly, the clinical significance of ASA has not yet been fully elucidated. The relationship between ASAs and cardiac arrhythmias have been evaluated in many studies and case reports [3-7]. The prevalence of supraventricular tachycardia in a 50 cases study has been reported to be $40 \%$ by Schneider [5]. While the prevalence of supraventricular tachycardia has been reported to be $57 \%$ by Longhini [7] and $45 \%$ by Morelli [6] in the smaller series.

It is unknown whether the ASA itself or associated structural and functional abnormalities are related to the pathogenesis of atrial arrhythmias [4-6,8]. There are only few case reports or retrospective studies that analyse the association between ASA and atrial arrhythmias [9-16]. Some studies [6,15,16] showed a positive association between ASA and supraventricular arrythmias, whereas others $[5,17,18]$ did not confirm the relationship. Deveci
[15] reported that the prevalence of supraventricular arrhythmias was significantly higher in a group of 66 young patients with echocardiographic diagnosis of ASA without comorbidities in comparison to a control group of 62 healthy volunteers (43.9 vs. $8.1 \%, \mathrm{P}<0001$ ). In the study by Morelli [6], the group of 20 patients with ASA showed a higher prevalence of supraventricular arrhythmias with respect to the control group of 19 healthy individuals. On the contrary, the prospective study by Schneider [5], including 50 consecutive patients with ASA, did not show a clear association between supraventricular arrhythmias and the presence of ASA.

Similar results were also obtained in the study by Miga [17], in which the prevalence of ASA was not significantly different in a group of 30 infants with supraventricular arrhythmias compared with a control group of 30 infants without any arrhythmias (13\% vs. 7\%, difference not significant; $n=30$, respectively). Vincenti [19] have noted that nearly half of the paroxysmal atrial fibrillation attacks were induced following a supraventricular ectopic beat. The study of Deveci [15] showed that the most common supraventricular tachycardias in patients with ASA are frequent supraventricular extrasystoles, which enrolled greater than 2000 supraventricular extrasystoles were detected in $27.3 \%$ of ASA patients within 24 hours. It is confirmed that ASA can act as an arrhythmic focus, 
generating focal atrial tachycardias [20]. What is the proarrhythmia mechanism of ASA? Evidence given by two studies that sinus impulses are conducted in a heterogeneous and anisotropic manner within the atrial tissue due to an irregular physical structure and differentiated microstructure of the atrial myocardium [21,22]. In ASA patients right and left atrial appendage function are impaired, the biatrial dysfunction may cause arrhythmia [23].

Morelli [6] confirmed a clear etiopathogenetic relationship between a large ASA and re-entry related atrial tachycardia, they believed the re-entry mechanism could be dependent on an electro anatomical barrier and/or different electrophysiological properties between ASA and the remaining atrial septum. Deveci [15] believed that the heterogeneity of atrial macro- and microgeometry caused by ASA may lead to changes in electrophysiological dynamics of the atrial myocardium, which in turn leads to more frequent atrial extrasystoles and induces atrial fibrillation attacks. Deveci [15] also found that the P-wave dispersion was significantly increased in patients with ASA compared to the control group. Prolongation of conduction has been documented both by 12-lead surface electrocardiogram and by a signal-averaged electrocardiogram recording to have a longer P-wave duration [24]. In the opinion of Muser D and colleague, the presence of ASA is indeed a structural element favoring the occurrence of atrial tachycardia and this is probably due to the abnormalities of both functional and anatomical characteristics of the atrium, including dispersion of the action potential and appearance of re-entrant circuits [16]. In all, although the relationship between ASA and supraventricular tachyarrhythmias is also controversial, more and more evidences tend to support the proarrhythmia mechanism of ASA.

\section{References}

1. Mattioli AV, Aquilina M, Oldani A, Longhini C, Mattioli G (2001) Frequency of atrial septal aneurysm in patients with recent stroke: preliminary results from a multicenter study. Clinical Research in Cardiology 24(4): 297-300.

2. Gallet B, Malergue MC, Adams C, Saudemont JP, Collot AM, et al. (1985) Atrial septal aneurysm--a potential cause of systemic embolism. An echocardiographic study. British Heart Journal 53(3): 292-297.

3. Morales R, Bokowski JW, Nguyen H, Awad SM (2019) A Proposed Etiology for Atrial Tachyarrhythmia in Neonates with Atrial Septal Aneurysms. Pediatric Cardiology 40(1): 230-233.

4. Mügge A, Daniel WG, Angermann C, Spes C, Khandheria BK, et al. (1995) Atrial septal aneurysm in adult patients. A multicenter study using transthoracic and transesophageal echocardiography. Circulation 91(11): 2785-2792.

5. Schneider, B Hofmann, T Meinertz T (1999) Is there an association of atrial septal aneurysm with arrhythmias? Cardiology 91(2): 87-91.

6. Morelli S, Voci P, Morabito G, Sgreccia A, De Marzio P, et al. (1995) Atrial septal aneurysm and cardiac arrhythmias. International Journal of Cardiology 49(3): 257-265.

7. Longhini C, Brunazzi MC, Musacci G, Caneva M, Bandello A, et al. (1985) Atrial septal aneurysm: echopolycardiographic study. American Journal of Cardiology 56(10): 653-656.
8. Janion M, Kurzawski J (2007) Atrial fibrillation in patients with atrial septal aneurysm. Cardiology Journal 14(6): 580-584.

9. De Ridder, S Cramer, MJ Ernst JM, Jaarsma W (2003) Giant multiperforated atrial septal aneurysm in a patient with paroxysmal atrial fibrillation. European Journal of Echocardiography 4(2): 154-156.

10. Armengol Rofes AJ, Granados Trabalón AM, Rovirosa Franch M, Garbayo Solana J, Serrano Durán M, et al. (1996) Supraventricular cardiac arrhythmia and fenestrated aneurysm of the interatrial septum in a newborn infant. Anales Espanoles de Pediatria 44(1): 63-64.

11. Perrotta S, Guarini P, Accadia M, Canciello M, Spadaro P, et al. (1995) Atrial septal aneurysm. Report of two clinical cases and review of the literature. Minerva Cardioangiologica 43(7-8): 339-343.

12. Livneh A, Langevitz P, Vered Z (1994) Atrial septal aneurysm and paroxysmal atrial fibrillation. Harefuah 126(8): 441-442, 491.

13. Toro L, Weintraub RG, Shiota T, Sahn DJ, Sahn C, et al. (1994) Relation between persistent atrial arrhythmias and redundant septum primum flap (atrial septal aneurysm) in fetuses. American Journal of Cardiology 73(9): 711-713.

14. Rice MJ, McDonald RW, Reller MD (1988) Fetal atrial septal aneurysm: a cause of fetal atrial arrhythmias. Journal of the American College of Cardiology 12(5): 1292-1297.

15. Deveci OS, Aytemir K, Okutucu S, Tulumen E, Aksoy H, et al. (2010) Evaluation of the relationship between atrial septal aneurysm and cardiac arrhythmias via P-wave dispersion and signal-averaged P-wave duration. Annals of Noninvasive Electrocardiology 15(2): 157-164.

16. Muser D, De Biasio M, Rebellato L, Proclemer A (2011) Is there a relationship between atrial septal aneurysm and atrial tachycardia? Journal of Cardiovascular Medicine 12(9): 666-668.

17. Miga DE, Case CL, Gillette PC (1996) Interatrial septal aneurysms and atrial arrhythmias in infants. American Heart Journal 132(4): 776-778.

18. Ozlem M Bostan, Ergun Cil, Ilker Ercan (2007) The prospective followup of the natural course of interatrial communications diagnosed in 847 newborns. European Heart Journal 28(16): 2001-2005.

19. Vincenti A, Brambilla R, Fumagalli MG, Merola R, Pedretti S (2006) Onset mechanism of paroxysmal atrial fibrillation detected by ambulatory Holter monitoring. Europace 8(3): 204-210.

20. Hanley PC, Tajik AJ, Hynes JK, Edwards WD, Reeder GS, et al. (1985) Diagnosis and classification of atrial septal aneurysm by twodimensional echocardiography: report of 80 consecutive cases. Journal of the American College of Cardiology 6(6): 1370-1382.

21. Spach MS, Dolber PC (1986) Relating extracellular potentials and their derivatives to anisotropic propagation at a microscopic level in human cardiac muscle. Evidence for electrical uncoupling of side-to-side fiber connections with increasing age. Circulation Research 58(3): 356-371.

22. Spach MS, Miller WT 3rd, Geselowitz DB, Barr RC, Kootsey JM, et al. (1981) The discontinuous nature of propagation in normal canine cardiac muscle. Evidence for recurrent discontinuities of intracellular resistance that affect the membrane currents. Circulation Research 48(1): 39-54

23. Demir M, Ozmen G, Keçoğlu S, Günay T, Melek M (2012) Right and left atrial appendage function in patients with atrial septal aneurysm without patent foramen ovale. Acta Cardiologica 67(4): 457-460.

24. Kawano S, Hiraoka M, Sawanobori T (1988) Electrocardiographic features of $\mathrm{P}$ waves from patients with transient atrial fibrillation. Japanese Heart Journal 29(1): 57-67. 


\section{ISSN: 2574-1241}

DOI: 10.26717/BJSTR.2019.15.002654

Long Yang. Biomed J Sci \& Tech Res

(c) (i) This work is licensed under Creative

Submission Link: https://biomedres.us/submit-manuscript.php

A Assets of Publishing with us
BESEARCHES
- Global archiving of articles
- Immediate, unrestricted online access
https://biomedres.us/

